- Article type: paper

- Date text written or revised = May 2020

- Number of words in main text $=4991$

\title{
Stakeholder perceptions of the Considerate Constructors Scheme in UK Construction
}

\section{Author 1}

- Greg Watts, BSc (hons), PgCert, FHEA, EngD, MRICS

- School of Science, Engineering and Environment, University of Salford, UK,

\section{Author 2}

- Anthony Higham, BSc (hons), PgCert, MSc, PhD, MRICS, MCIOB, FHEA

- School of Science, Engineering and Environment, University of Salford, UK,

\section{Author 3}

- Ali Alotaibi, BSc (hons), PhD

- College of Engineering, Shaqra University, Dawadmi, Ar Riyadh, Saudi Arabia

Greg Watts, G.N.Watts@Salford.ac.uk 
Stakeholder perceptions of the Considerate Constructors Scheme in UK Construction

\section{Abstract}

The Considerate Constructors Scheme was introduced in 1997 to improve the image of the UK construction industry and has grown dramatically with over 6,000 construction and infrastructure projects registered valued at $£ 43$ billion. Whilst evidence exists that the industry's image is improving, there is little research into the CCS perceptions of those tasked with the schemes delivery. It is not clear if contractors engage with CCS willingly as proactive participants or succumb to the requirements of clients to simply win work. The aim of this paper is to gain an insight into contractor perceptions of CCS to ultimately aid clients and contractors in their delivery of the scheme, and ensure the CCS delivers the maximum benefit for stakeholders. A case study of a single infrastructure project registered with the CCS is utilised. All CCS documents were critically analysed, and interviews conducted with clients, the contractor and residents. The findings contribute to an unexplored area of research and reveal the motivations behind why a contractor engages with the CCS, the advantages and drawbacks in the scheme's current enactment, and key lessons on how the CCS could be administered and delivered more effectively for the benefit of all stakeholders.

\section{Keywords chosen from ICE Publishing list}

Keyword 1; Contracting.

Keyword 2; Corporate Responsibility

Keyword 3; Sustainability 


\section{Stakeholder perceptions of the Considerate Constructors Scheme in UK Construction}

1

2

3

4

5

6

7

8

9

10

\section{Introduction}

The importance of the engineering and construction industry to the economies of most countries cannot be underestimated. .Despite this importance the industry has always suffered from a negative public imagine and a bad reputation. The fact that almost all projects are undertaken in the highly visible public arena and cause some sort of short term inconvenience cannot help this, but then neither can the industry's disruptive nature and resource exploitative use of raw materials (Barthorpe, 2010).It has been argued therefore, that the construction industry has ample reason to look for methods of improving their reputation by becoming more environmentally and socially responsible (Murray and Dainty, 2009). To this end, numerous initiatives have been delivered with the aim of improving the image of the engineering and construction sector, all arguably resulting in differing degrees of success. One such initiative that began life from inside of the construction industry itself is called the Considerate Constructors Scheme (CCS). This is a voluntary scheme aimed at improving the image of the construction industry and is now widely adopted on thousands of UK engineering and construction projects every year. The CCS claim to have made a positive difference to the industry's image with numerous case studies released as evidence of the positive impacts the Scheme brings (CCS, 2019). However, despite such an impressive take up and well publicised benefits for all involved, there is relatively little research on the benefits CCS brings or on the wider perceptions of CCS amongst construction professionals. Therefore, it is unknown if clients and contractors engage with the requirements of the scheme willingly as proactive partners or are simply abiding by requirements placed upon them to simply win work. This could mean the CCS is not being delivered and enacted as effectively as it could be to take advantage of its wide market adoption. Gaining an insight into the perceptions and interpretations of CCS practitioners, contractors and clients, can help achieve a better understanding of the Scheme. This greater understanding will ultimately aid clients and contractors in their delivery of the Scheme, and ensure the CCS delivers the maximum possible benefit for all stakeholders.

\section{The image of the UK construction Industry}

The engineering and construction industry encompasses the design, construction, maintenance and demolition of assets, buildings, engineering and infrastructure works. It accounts for 
approximately $6 \%$ of the UK economic output with an annual value of over $£ 113 \mathrm{bn}$ (Rhodes, 2019). The benefits of the industry are also wider, in that the work undertaken improves the very fabric of society (Glass and Simmonds, 2007). Irrespective of such benefits, the construction industry has always been negatively perceived, with positive success stories often overlooked yet the slightest of environmental or societal transgressions are widely publicised (Barthorpe, 2010). In this respect the industry does not help its own cause as construction operations often result in increased dust, noise, water and air pollution (Glass and Simmonds, 2007). In addition to the adverse health impacts, a reduction in the quality of life of stakeholders local to projects, an increase in anti-social behaviour around sites and an increase in site traffic related congestion can all contribute to wider economic loss (Glass and Simmonds, 2007). Such impacts then lead to negative publicity which in turn attracts hostility from stakeholders (Curran et al., 2019) and has ultimately resulted in a decades old image problem the industry needs to address (Murray et al., 2010).

Improving the image of construction has been described as central to the industry's future growth (Petter, 2019). Numerous attempts have been employed to address construction's image problem, both from outside the industry and from within. For example, legislation has been introduced by the Government such as the Local Democracy, Economic Development and Construction Act (2009) to put in place procedures to help resolve disputes and improve the financial treatment of the construction supply chain (Hughes et al., 2015). Such legislation is designed and implemented with the intention of forcing organisational behaviour change by introducing requirements enforceable in a criminal court. Another example of legislation applicable to the construction industry is that of The Public Services (Social Value) Act (2012). The Social Value Act compels public bodies to compare the social value contractors can bring to projects in addition to the traditional criteria of time, cost and quality - thereby encouraging contractors to become involved in more social value activities (Watts et al., 2019). Initiatives arguably launched from both within and external to the construction industry include the idea of Corporate Social Responsibility (CSR). Whilst no widely agreed definition of CSR has been reached, CSR has been broadly described as an umbrella term encompassing an 
61 organisation's legal, ethical, economic, and voluntary strategies and practices that have an impact upon on society and the environment (Watts et al., 2016). Whilst evidence exists of businesses from hundreds of years ago embracing the principles of CSR, the modern advent of CSR in the general business domain can be traced back to the publication of the book 'Social Responsibilities of the Businessman' (Bowen 1953). It is argued that business prosperity should result in more philanthropic activity and that wealthy individuals had a responsibility to give back to society (Bowen, 1953). CSR then grew as a concept over the proceeding decades to an item high on the agenda of most businesses and stakeholders (Carroll, 2015). A survey on the CSR practices of 4,900 organisations across 49 countries reveals that CSR has been widely embraced throughout all industries by numerous leading organisations as a part of their core business identity (KPMG, 2017).

The construction industry has however, been described as lagging behind others when it comes to embracing CSR (Glass, 2012). The CSR survey further reveals that the number of construction companies reporting on CSR has fallen from 2015 and that engineering and construction companies are less likely to report on CSR than companies in other industries such as financial services, chemical and the automotive industry (KPMG, 2017). It is argued this is due to the fragmentation of the construction industry as well as the industry's short-term focus and reactive attitude (Alotaibi et al 2019). However, within the UK construction industry examples of CSR practices have been discussed with initiatives such as allowing employees fully paid work days in which they can volunteer at charitable organisations (Loosemore and Bridgeman, 2018) and providing work experience placements to those wishing to gain construction experience (Morton et al., 2014). Whilst it cannot be said that all businesses operating within the construction industry engage with and report upon CSR, such practices are becoming more commonplace. This is beneficial for all parties involved, as whilst there are acknowledged widespread benefits to intended recipients of CSR activities, there are also numerous benefits to be experienced by the organisation(s) responsible. These include an enhanced organisational reputation, appeal as a workplace of choice for potential staff (Du et al., 2010) and increasing both job satisfaction and staff retention (Brammer at al., 2007) as well as improved financial performance through being an organisation of choice for customers 
91 (Saeidi et al, 2014). It can be argued that all these benefits are directly achieved from an organisation adopting CSR practices, thereby helping to improve the organisations image amongst stakeholders.

Finally, initiatives have been launched from within the construction industry itself with the aim of improving its image. The most notable of these is arguably the Considerate Constructors

Scheme. The CCS shares many principles with CSR such as attempts to address the negative industry image and improve the often troublesome relationship between the construction and its stakeholders (Glass and Simmonds, 2007). One of the driving forces of the CCS is the idea that to improve the image of construction, CSR practices need to be implemented at a project level (Curran et al., 2019).

102

\section{The Considerate Constructors Scheme}

Founded in 1997 the CCS is an independent body created by the construction industry itself with the aim of improving the image of construction through the implementation of a voluntary code of considerate practice (Barthorpe, 2010). The primary aim of the CCS is to improve the image of construction through competent management, environmental awareness and 'neighbourliness' (CCS, 2019). Indeed, it is argued that CCS plays an important role in promoting the industry's positive image and helping raise standards year on year (Petter, 2019). You can register with the CCS as a construction project, a contractor, a supplier or as a professional service organisation. At a fundamental level the CCS is all about creating a link between the site and the local stakeholders. If such stakeholders witness practices they deem

113 not in keeping with a modern construction industry, they can quickly report this to the CCS who can take action, usually through the designated Scheme Monitor (SM). A project registered with the CCS will be visited at set intervals by the SM who assesses the project using their own discretion, and awards the site a score against a standard 'code of considerate practice'.

The SM's are arguably key to the success of the CCS, and usually consist of construction professionals who want to help maintain and improve industry standards. To this end an annual awards event is held to reward and acknowledge the highest scoring projects of that year. With 

construction projects registered with the CCS, with the total project value exceeding $£ 43$ billion

123 (CCS, 2019). It is also important to note that the scheme gets no government funding, is a nonprofit organisation and is financed purely from the fees paid from contractors voluntarily signing up (Murray et al., 2010).

As the purpose of the CCS is to improve the image of the UK construction industry and encourage engagement with both the local community and wider stakeholders (Curran et al., 2019) the Scheme has been described as a perfect framework to address societal concerns and attempt to rectify the negative image of the industry (Glass and Simmonds, 2007). Companies that sign up are compelled to consider the impact their practices have on staff, contractors and the environment. Such a framework is governed by the scoring of a project against five key headings: appearance, community, environment, safety and workforce. There is a minimum expectation against each heading with the score of 5 representing 'compliance'. The Scheme Monitors (SM) are responsible for visiting each project and initially award an indicative score against each heading. These indicative scores are then revised as further visits are held. Finally a validated score is provided. The scoring mechanism has matured and evolved since its initial conception with the most recent iteration in January 2019. The purpose of this is to ensure the CCS remains the vanguard of standards and at the forefront of encouraging, fairly scoring and rewarding both company and site based innovation. Since 2019 scores against each heading are out of 9 , giving a total of 45 . At the discretion of the SM five additional points are then available to be awarded for the five best examples of innovation as put forward by the project

143 team.

145 Murray et al., (2010) explore the actions of the construction team who successfully delivered

146 'the most considerate construction site' as awarded at the annual CCS award ceremony in

147 2009. It was found that examples of considerate behaviour by contractors can include 148 maintenance of surrounding vegetation, implementation of temporary speed limits, rearranging 149 the programme of works so noisy and dusty activities occur in school holidays, reducing waste and pollution, and maintaining high levels of communication with neighbours (Murray et al., 
151 2010). The research also revealed that innovative and unique CCS practices are often the result

152 of a leadership team that encourage and support creative solutions and activities proposed by

153 those on site. It should however, be added that the CCS requirements are purposefully broad in

154 nature to serve more as a platform for each site to base their actions and behaviours on.

155 Therefore, contractors who are larger and more experienced with the CCS typically do not need

156 the CCS to drive their CSR behaviours. Such contractors may tend to have innovative and

157 creative initiatives more readily available when compared to smaller contractors who do not

158 have much experience with the CCS. This is where the broad nature of the requirements are

159 advantageous as they allow all companies and sites to participate. Murray et al., (2010) go

160 further and report that a proactive rather than passive site management team is needed in

161 order for a construction project to achieve a high CCS score. Overall it is concluded that the

162 CCS is helping to reduce the negative impact of construction works and therefore helping to

163 improve the image of the general construction industry (Murray et al., 2010). A single company

164 case study of different live construction projects found that a more structured relationship

165 between the construction site and main stakeholders, such as that facilitated by the CCS, is

166 needed to enhance the image of construction (Glass and Simmonds, 2007).

167

168 An in-depth study by Curran et al (2019) explores the CCS perceptions of UK construction

169 contractors and finds that perceived advantages include the raising of general industry

170 standards, improving of relationships with stakeholders and an increasingly positive image of

171 the industry as a whole. It has also been argued that CCS is a driver of contractors improving

172 their waste management practices (Adeji et al., 2018). Reported disadvantages to the CCS

173 include the costs associated with the registration and implementation of changes needed, the

174 subjectivity and inconsistency of inspectors and scores the sites receive and the weighting

175 applied to activities the contractors believe will not yield a high social and environmental impact

176 for the time and resources required (Curran et al., 2019). A previously reported disadvantage is

177 also that some construction professionals with responsibility for delivering the CCS activities on

178 a site level have stated it has been easy to achieve the minimum standards (Murray et al., 2010)

179 and therefore it could be argued that the CCS does not push those contractors hard enough

180 who are only aiming to achieve the minimum standards. However, despite the increasing 
numbers of projects signing up to the CCS, there is limited research into the perceptions of the scheme amongst construction professionals and wider stakeholders. Therefore, it is unknown if clients and contractors engage with the requirements of the CCS willingly as proactive partners or are simply abiding by requirements placed upon them to simply win work. The aim of this paper is to understand the motivations and key stakeholder perceptions of the CCS on a project level. Gaining an insight into the perceptions and interpretations of CCS practitioners, contractors and clients can help achieve a better understanding of the CCS and address the current gap in research. It may be that the CCS is not being delivered and enacted as effectively as it could be to take advantage of its wide market adoption and so therefore, a greater understanding will ultimately aid clients and contractors in their delivery of the scheme, and ensure the CCS delivers the maximum possible benefit for all stakeholders.

\section{Method}

194 A single case study was identified of a construction project valued at £1million located in the North East of England. The site is on the outskirts of a major city in a semi-rural area, set back from the main road adjacent to farm land. A case study is a widely used analysis method in the business and management fields and allows for an intensive and detailed exploration of a particular phenomena (Bell et al., 2019) However, one noted limitation of the case study design is a lack of generalisability as what is identified and investigated in one case may not occur in another (Walliman, 2016). However, in this instance, as many construction projects are currently registered with the CCS or have been previously, and case study research has been used in some of the CCS research conducted to date (see Glass and Simmonds, 2007; Murray et al., 2010) it was determined that a case study design would enable a deep and insightful investigation into how CCS was perceived by individuals from the same project.

As part of the case study an analysis of all documents relating to the CCS on the project were reviewed. These documents included the original CCS requirements issued by the client during procurement, the CCS information submitted by the successful contractor as part of their tender, the elements of the signed construction contract that related to the CCS, and finally all contractor documents involved in the delivery of the CCS requirements such as invoices, 
211 timesheets, meeting minutes, and completed scoring mechanisms. The scope of the document

212 review was included any document that mentioned or had indirect reference to the CCS

213 required or delivered on the project. Nine semi-structured interviews were conducted with

214 different project stakeholders as part of the case study. This allowed questions to be asked that

215 focused on relevant topics whilst allowing flexibility to pursue any emerging lines of enquiry that

216 were of interest to the research (Bell et al., 2019). For the client's consultant this consisted of

217 the Project Manager (PM) and Quantity Surveyor (QS). Interviews were also conducted with the

218 contractor's staff including the PM, QS and Construction Manager (CM). Two interviews were

219 also conducted with site operatives (SO) from two different sub-contractors who worked on the

220 project and two interviews with local residents. One resident was a farmer who owned land

221 adjacent to the project and another was the owner of a small local business. All interviewees

222 had direct responsibility for delivering an aspect of the CCS on the project, or were directly

223 impacted by the project, and so were best placed to inform the research.

224

225 Narrative analysis was used both as a method of discussion and as a tool for analysis allowing the interview questions to be framed from the perspective of requesting stories from interviewees so that their motivations and perceptions can be elicited (Griffin and May, 2011). Narrative analysis essentially encourages a participant to be the teller of stories allowing them to recall events, and is a particularly good method of understanding how change is interpreted by individuals within that organisation and the culture of the organisation itself (Bell et al., 2019).

231 Narrative analysis encourages the grouping together of relevant interviewee responses to allow trends and patterns to be identified and people's thoughts, stories and opinions to be explored allowing deeper meanings to be understood (Loosemore and Bridgeman, 2018).

\section{5. Results}

236 The critical analysis of the key CCS documents revealed interesting findings and also formed

237 the basis of some interview questions. The documents consisted of the original CCS requirements issued by the client to potential contractors, the tender return of the successful contractor, and all contractor documents involved in delivering the CCS including invoices, timesheets, meeting minutes, and completed scoring records. The project contract containing all 
241 contractually agreed CCS requirements was also reviewed. Interestingly the details included in

242 the originally issued project requirements, those returned by the contractor in their price, and

243 those contained in the project contract were somewhat sparse and where information was

244 included, it was rather vague. For example the client's tender invitation documents consisted of

245 four sentences stating the achievement of an 'Excellent' status was a high priority, the

246 contractor should achieve an average score of 40 in all CCS audits, and that the contractor

247 should include a sum to help this to be achieved. The successful contractor's tender return

248 consisted of a lump sum cost to deal with all CCS requirements but no further breakdown.

249 Analysis revealed this amounted to $2.91 \%$ of the overall price submitted for the project. The

250 contract simply contained the client's CCS tender information and the contractor's lump sum

251 price.

252

253 From a review of these initial documents it was impossible to see what CCS activities were expected by the client and what had been included for by the contractor. The meeting minutes, invoices and contractor CVR reports however, gave a more detailed insight into the CCS activities conducted. Firstly, it is important to note that the final cost of all activities directly related to the CCS requirements was almost double what the contractor had originally budgeted for $(4.85 \%)$. As the contract was based on the NEC Option A the price the contractor had attributed to the CCS element was their own to manage, and additional costs couldn't be claimed for. This was raised during the interviews with the client's PM and QS who were both of the opinion it was the contractors responsibility to include a sum in the contract to ensure a score of 40 was achieved at each visit, and that no requests for additional monies due to increased costs incurred would be entertained. Interviews with the contractor QS revealed that the CCS scores contractually required on the project were achieved, and that a Compensation Event (the contractual mechanism by which increased costs are claimed by the contractor) had been applied for and rejected. The interview with the contractor PM revealed that due to the ambiguity of the CCS requirements at pre-tender stage, a figure was included in their tender price without any real consideration or calculation of what could be achieved within this amount. It could therefore be argued that the resulting increase in costs from this lack of thought is ultimately the contractors fault, and a lesson learnt the hard way. However, this also illustrates 
271 the very real financial ramifications that can occur from the lack of CCS understanding. Arguably

272 this lack of understanding is driven from the top down and the client in this instance is ultimately

273 benefiting as they received the project CCS score they desired, but at a reduced cost as the

274 contractor had to foot the bill for the CCS requirements that went above and beyond he figure

275 they had initially included.

276

277 A review of the timesheets, meeting minutes and score sheets revealed that initiatives on the 278 project included extensive site signage including CCS specific 'hunt for hazards' and 'spot the 279 job' posters, a bug and hedgehog 'hotel' to encourage local wildlife, the cleaning and trimming back of overgrown foliage around the site, tokens from a local dry cleaners allowing site operatives to get site clothing cleaned locally for free, and plenty of registers for recording local spend on materials, carbon dioxide involved in site traffic and commuting to and from site, and

283 the amount of electricity used on site. The scoring documents revealed in meeting the requirements of the client (to achieve a score of 40 ) the project received consistently high scores. This was confirmed by the client's PM who viewed the project as a success and was satisfied with all CCS activities and the scores received. However, the perspective of the contractor QS was that the CCS was not a success due to the vast overspend incurred. It was interesting the reveal the different areas of focus for judging the Scheme as successful, with the client focussing on the scores achieved (which ultimately reflect the positive impacts on both the site staff and the wider local community) and the contractor focussing on the financial overspend. This illustrates how the ambiguity of CCS information at the start of a project can lead to different perspectives on CCS success at the end of the project.

294 The motivation for the client's PM to implement the CCS on the project was due to requests 295 from the client themselves that the project do all it can during the construction phase to maximise benefit to the local community and minimise the chance of local disruption resulting in negative opinions of the project. CCS was viewed by the client as the perfect vehicle to achieve this. The perceptions of CCS by the client's PM and QS were that it is a good and worthwhile scheme. Despite their obligation to implement it from the client, they believed CCS in general 
and on the project in question specifically, to be worthwhile and made a positive difference to both the site operatives and local community.

302

303 When motivation was discussed with the contractor, the PM and QS agreed that they only

304 registered the project with the CCS due to requirements of the client. They also went further and argued that the CCS was not focused enough on improving one aspect of construction, and they didn't believe in the positive benefits CCS could bring and so therefore only paid lip service to the requirements. Ensuring minimum engagement to allow efforts to be focused on the 'actual construction work'. Both the contractors QS and PM also agreed that their perceptions of the Scheme were influenced by the failed CE they submitted in which they sought to claim the additional CCS expenses incurred. The initial misunderstanding of how the costs associated with delivering the CCS requirements would be administered had ultimately resulted in a lack of engagement with the CCS from the contractor's management team. The contractors CM however, had a slightly different view, as they believed that the CCS could be a 'catalyst for

314 wider change' referring to both the immediate differences that could be seen on site and the improvements that could be made across the industry as a whole. Although the CM did follow

316 this up with several responses on how in its current form and focus the CCS is 'lost' and is not

317 taken seriously by most contractor staff and site operatives. The CM argued that the CCS is

318 largely full of 'silly niceties... and all about beautification nonsense' and that drawing attention to 319 the project with signage is the worst thing can be done due to the increased risk of anti-social 320 behaviour. Plus, all the additional signage requirements on site, due to the amount of registers and notices now required, has led to important site messages becoming lost in a 'daily barrage of nonsense'. However, this was the first time the CM had worked on a CCS registered project and admitted to feeling unsupported by the wider contractor management team in the delivery of

324 the CCS requirements. Despite such negativity, under the banner of CCS the contractor did introduce several initiatives on site that achieved and surpassed the contractual CCS requirements. Positive impacts on both site personnel and the wider community were also discussed reinforcing findings in the literature that CCS adoption leads to positive impacts

328 (Curran et al., 2019; Adeji et al., 2018) and builds on this understanding by introducing the idea 
that benefits are still achieved with the introduction of the CCS, even when the contractor does not fully embrace the scheme.

The interviews with the SO's confirmed this, in that they felt on projects registered with the CCS, there were many more factors to be aware of, and much more 'intrusion' into their actions on site. Both SO's listed several aspects of CCS on the current project that they saw as positive and several they saw as negative. Overall both SO's had a more negative than positive perception of the CCS, with the reasons largely due to the additional intrusion and scrutiny they felt they were under, and again, much like the PM and QS, the SO's stated that they only complied with the minimum of CS requirements. Interestingly however, both SO's reported that some of their experiences of the CCS were due to how it had been delivered on site, with inconsistent and changing requirements as the site team would decide upon what approach and initiatives they would take, only to change their minds at a later date. Both SO's also believed the PM, QS and CM had negative perceptions of the CCS. This perhaps reveals more about the management style required in the successful delivery of CCS objectives, with a clear and consistent approach required with communication of the initaives as important tof the initaives themselves. Such findings resonate with arguments in the literature that successful CCS adoption is driven by proactive rather than passive site management (Murray et al., 2010).

348 When the two local residents were interviewed, it was found they had quite different perceptions of the construction project. Firstly, neither resident directly discussed the CCS, and seemed unaware of the scheme and its intentions. They had only good things to say about the project despite the noise during the day time that directly impacted upon the farmers operations, and the fact the farmer was unable to use the field closest to where the project was located due to noise and dust generated during the works. The interviews revealed that despite having no knowledge of the CCS itself, the farmer's positive perceptions of the work were due to actions that were undertaken by the contractor as a result of the CCS. The second local resident interviewed, a local business owner, was not happy with the project as they saw no local benefit to the immediate works, despite acknowledging the importance of the infrastructure asset itself. The local business owner was also inconvenienced by congested traffic and speed restrictions 
359 (albeit begrudgingly admitting the slower roads were safer). Also, somewhat interestingly, in 360 agreement with the contractors $\mathrm{CM}$, the local residents felt the attention drawn to the project

361 with increased signage was unsightly for the area, and would increase anti-social behaviour.

362 This was despite the fact that no anti-social behaviour was ever recorded on the project during

363 its duration.

364

365 4. Conclusions

366 This paper identified a research gap in existing construction industry literature regarding how

367 the Considerate Constructors Scheme is perceived by those involved with and impacted by its delivery. A case study of a single construction project was undertaken which consisted of analysis of all the tender, contractual and commercial CCS project data, and nine semistructured interviews conducted with the project stakeholders. The analysis of all contractual and commercial CCS data revealed vague requirements in both the tender documentation and contract had led to a misunderstanding between the client's consultants and contractor resulting in the contractor under-pricing the work involved in the CCS delivery. This led to disagreements on site and left the contractor feeling disengaged from the CCS.

The interviews also revealed that whilst the client's PM and QS believed in the benefits CCS could bring to both the specific project and the wider construction industry, the contractor staff were more negative towards the CCS. This could explain why in this instance, the contractor engaged with CCS as a requirement to win work, and once the project had begun attempted to complete the minimum stipulated requirements. However, it is important to note that this was the first experience of CCS for many of the contractor staff, and due to a misunderstanding between the contractor and client's consultants the contractors costs to successfully deliver the

383 CCS (as contractually required) were far more than originally anticipated and priced for.

384 Nevertheless, if this was to be replicated nationwide across all CCS registered projects with contractors engaging in the same way, the positive impacts arising from delivery of CCS initiatives nationwide may not be as effective as they could be. Where positive perceptions of the CCS did exist amongst the contractor's PM, QS and CM, it was felt the CCS was misguided and needed more focus on single issues of importance, with clear unaccompanied 
communications so that all resources could be focussed for maximum positive impact. However, the research also revealed that despite negative CCS contractor perceptions resulting from a lack of CCS understanding the Scheme did result in positive experiences for both the site team and local community. The interviews with local residents also revealed that their perceptions of the construction project differ. Whilst neither resident was aware of the CCS, the resident who was directly impacted by a CCS initiative had a favourable perception of the construction project. However, the second resident interviewed was inconvenienced by the construction works and felt the increased signage (due to the CCS) may attract anti-social behaviour by drawing attention to the site and so had a negative perception of the project. This was despite no record of anti-social behaviour actually occurring. However, the resident's concerns were to do with the works themselves, and not the CCS. Therefore it could be speculated that the CCS actually served to reduce some of the resident's concerns over the project. It could therefore be concluded that even in instances where the CCS is not fully understood or embraced by the site team; positive impacts (or less negative impacts) are still felt both within the project and in the local community. Going forward therefore, clear communications from the client to the contractor would assist with contractor understanding, which would in turn enable a more effective delivery of the CCS initiatives, potentially minimising the negative perceptions felt amongst contractor staff and maximising the potential positive impacts of the CCS for all stakeholders.

A limitation of this study is the use of only a single case study as it limits the generalisability of the results. The project was also of a smaller value, in a semi-rural location and the contractor

411 was inexperienced in CCS delivery. A more experienced contractor, a higher value project and in an urban setting may not experience the same restraints and issues as highlighted in this

413 study. However, as the CCS can be used on all schemes regardless of size and location, and

414 by all contractors regardless of experience, it is felt this paper offer an interesting insight into

415 previously underexplored areas of CCS delivery.

416 One recommendation of this paper is for further research into the perceptions of the CCS

417 across a range of stakeholders over multiple case studies, to see if the perceptions identified in 418 this case study can be generalised. Secondly it is recommended that those enforcing CCS use 
reconsider how contractor requirements are communicated. The CCS does bring benefits to all stakeholders even when the contractor shows little understanding and willingness to fully engage. Therefore if engagement could be increased amongst contractors, it would be interesting to see if and by how much the positive CCS benefits can be improved for all stakeholders, and in turn continue to improve the reputation of the wider construction industry.

\section{References}

Alotaibi, A., Edum-Fotwe, F., \& Price, A. D. (2019). Critical barriers to social responsibility implementation within mega-construction projects: The case of the Kingdom of Saudi Arabia. Sustainability, 11(6), 1755.

Adeji, S., Ankrah, N., Ndekugri, I and Searle, D. (2018). Sustainable Construction and Demolition Waste Management Comparison of Corporate and Project Level Drivers. In Gorse and Neilson (Eds) Procs 34th Annual ARCOM Conference, 3-5 September 2018, Belfast, UK, Association of Researchers in Construction Management. Barthorpe, S. (2010). Implementing corporate social responsibility in the UK construction industry. Property Management, 28(1), p.4-17. University Press. Oxford.

437 Bowen, H. (1953). Social Responsibilities of the businessman. New York: Harper \& Row.

438 Brammer, S., Millington, A. \& Rayton, B. (2007). The contribution of corporate

439 Carroll, A. (2015), Corporate Social Responsibility: The centrepiece of competing and 440 complementary frameworks. Organisational Dynamics. 44, p.87-96.

441 Considerate Constructors Scheme (CCS) (2019). About Us. Accessed at:

442 https://www.ccscheme.org.uk/ccs-Itd/what-is-the-ccs2/

443 Curran, M., Spillane, J and Clarke-Hagan. (2019). The Considerate Constructors Scheme.

444 Improving the Image of Construction, But How Considerate Are They to Contractors? In Gorse 445 (Ed) Procs 35th Annual ARCOM Conference, 2-4 September 2019, Leeds, UK, Association of 446 Researchers in Construction Management.

447 Du, S., Bhattacharya, C. and Sen, S. (2007). Reaping relational rewards from 
448 Glass, J. (2012). The state of sustainability reporting in the construction sector. Smart and 449 Sustainable Built Environment. 1(1), p87-104.

450 Glass, J and Simmonds, M. (2007). "Considerate Construction": case studies of current 451 practice. Engineering, Construction and Architectural Management. 44, 2, pp131-149.

452 Griffin, A, and May, V. (2012). Narrative analysis and interpretative phenomenological analysis. 453 In, Seale, C, Researching Society and Culture. 3rd Ed. Sage Publications. London.

454 Hughes, W., Champion, R. and Murdoch, J. (2015). Construction Contracts Law and 455 Management, 5th Ed. Routledge, Oxon.

456 KPMG. (2017), The Road Ahead; The KPMG Survey of Corporate Responsibility Reporting 457 2017. KPMG Global Sustainability Services 2017.

458 Loosemore, M and Bridgeman, J (2018). The Social Impact of Construction Industry Schools459 Based Corporate Volunteering. Construction Management and Economics. 36(5), p243-258. 460 Morton, P., Goodwin, A., Kellond, A., Close, K, and, Collins, J. (2011). Investing in the Future 461 Construction Workforce: CSR and Work Experience Placements. International Journal of 462 Construction Management, 11(2), p.49-58.

463 Murray, M., and Dainty, A. (ed.) (2009), Corporate Social Responsibility in the Construction 464 Industry. Taylor and Francis, London.

465 Murray, M., Forbes, D, and Mason, S. (2010). Considerate Constructors Scheme: Glenfarg

466 Water Treatment Works. Proceedings of the Institute of Civil Engineers. Engineering 467 Sustainability, p1-9.

468 Petter, M. (2019). Putting Civil Engineering at the Centre of Improving Construction's Image. 469 Proceedings of the Institute of Civil Engineers. Civil Engineering, Vol. 179. p55.

470 Rhodes, C. (2015). Construction Industry: statistics and policy. Nr 01432. House of Commons 471 Library. www.parliament.uk/briefing-papers/sn01432.pdf

472 Saeidi, S., Sofian, S., Saeidi, P., Saeidi, S.P. and Saaeidi, S. (2014). How does

473 social responsibility to organizational commitment. The International Journal of Human

474 Walliman, N. (2016). Social Research Methods. Sage Publications. London.

475 Watts, G., Dainty, A. and Fernie, S (2016). The Influence of Public Sector Procurement Practice 476 in Shaping Construction CSR. Procs 2016 Royal Institution of Chartered Surveyors COBRA 477 Conference, September, 2016. 
478 Watts, G., Dainty, A. and Fernie, S. (2019). Paradox and Legitimacy in Construction: how CSR

479 Reports Restrict CSR Practice. International Journal or Building Pathology and Adaptation.

$480 \quad 37(2)$, p231-246. 